\title{
СИСТЕМА ПРИНЯТИЯ РЕШЕНИЙ В ПРОГРАММЕ ЛЬГОТНОГО ЛЕКАРСТВЕННОГО ОБЕСПЕЧЕНИЯ
}

\author{
Р. У. Хабриев, А. П. Суходолов², Б. А. Спасенников³, Л. Ю. Безмельницына', \\ Д. О. Мешков ${ }^{1}$ \\ 1 Национальный НИИ общественного здоровья им. Н. А. Семашко, Г. Москва, Российская Федерация \\ 2 Байкальский государственный университет, г. Иркутск, Российская Федерация \\ ${ }^{3}$ НИИ Федеральной службы исполнения наказаний России, г. Москва, Российская Федерация
}

\author{
Информация о статье \\ Дата поступления \\ 13 декабря 2017 г. \\ Дата принятия к печати \\ 28 фревраля 2018 г. \\ Дата онлайн-размещения \\ 30 марта 2018 г. \\ Ключевые слова \\ Административное право; право \\ социального обеспечения; \\ нормативные правовые акты; \\ государственные программы; \\ льготное лекарственное \\ обеспечение; система принятия \\ решений; оценка технологий \\ здравоохранения
}

\begin{abstract}
Аннотация
В большинстве стран Европы, США и Канаде внедрена и уже более 20 лет функционирует система оценки технологий здравоохранения. В России также совершенствуются нормативные акты, регламентирующие правила формирования перечней лекарственных препаратов, но единая система принятия решений отсутствует. Цель: изучение системы принятия решений о включении препаратов в перечни льготного лекарственного обеспечения. Материалы и методы: проведено анонимное анкетирование 250 специалистов из Министерства здравоохранения России, фрармацевтических и страховых компаний, сотрудников медицинских университетов и врачей клинических специальностей. Результаты: была получена комплексная оценка системы принятия решений в области лекарственного обеспечения и определены перспективы ее совершенствования.
\end{abstract}

\section{THE DECISION-MAKING SYSTEM IN THE PROGRAM OF SUBSIDIZED PHARMACEUTICAL PROVISION}

\author{
Ramil U. Khabriev' ${ }^{1}$, Alexander P. Sukhodolov ${ }^{2}$, Boris A. Spasennikov ${ }^{3}$, \\ Lyudmila Y. Bezmelnitsyna ${ }^{1}$, Dmitry O. Meshkov' ${ }^{1}$ \\ 1 The N. A. Semashko National Research Institute for Public Health, Moscow, the Russian Federation \\ ${ }^{2}$ Baikal State University, Irkutsk, the Russian Federation \\ ${ }^{2}$ Research Institute of the Federal Penitentiary Service, Moscow, the Russian Federation
}

\section{Article info}

Received

December 13, 2017

Accepted

February 28, 2018

Available online

March 30, 2018

\section{Keywords}

Administrative law; social security law; normative legal acts; governmental programs; preferential provision of medicines; decision-making system; health technology assessment

\begin{abstract}
More than 20 years ago, the System of Health Technology Assessment was implemented in most European countries, the United States of America and Canada and it has been functioning ever since. There are, as well, some legislative acts regulating the rules for the formation of lists of medicinal drugs in Russia; however, a common decision-making system does not exist. Purpose: to study the decision-making system of including medicines onto the list of subsidized pharmaceutical provision. Content and methods: 250 specialists from the Ministry of Health, pharmaceutical and insurance companies, medical university staff and clinical physicians were surveyed anonymously. Results: comprehensive evaluation of decision-making system of medicines provision was obtained and prospects for improvement were determined.
\end{abstract}


Актуальность. Всемирная организация здравоохранения настоятельно призывает государства-члены рассмотреть вопрос ○ создании национальных систем оценки мероприятий и технологий в области здравоохранения. Первой такой организацией стал The National Institute for Health and Care Excellence (NICE), открытый в 1999 г. в Великобритании. Его основная функция разработка рекомендаций по выбору медицинских технологий для Национальной службы здравоохранения (National Health Service) Великобритании ${ }^{1}[1 ; 2]$. В Германии аналогичная структура - The Institute for Quality and Efficiency in Health Care: Germany (IQWiG)) - была открыта в 2003 г. ${ }^{2}$ [3; 4].

В России действует ряд нормативных актов, регламентирующих формирование перечней льготного лекарственного обеспечения ${ }^{3}$ в в частности постановление Правительства РФ «Об утверждении Правил формирования перечней лекарственных препаратов для медицинского применения и минимального ассортимента лекарственных препаратов, необходимых для оказания медицинской помощи» от 28 августа 2014 г. № 871, которое устанавливает порядок формирования перечней жизненно необходимых и важных лекарственных препаратов (далее - ЖНВЛП), дорогостоящих лекарственных препаратов, лекарственных препаратов для обеспечения отдельных категорий граждан, минимального ассортимента лекарственных препаратов. Согласно постановлению, за формирование перечней льготного лекарственного обеспечения

${ }^{1}$ National Institute for Health and Clinical Excellence. Guide to the methods of technology appraisal. London : NICE, 2007.

${ }^{2}$ IQWiG. Methods for Assessment of the Relation of Benefits to Costs in the German Statutory Health Care System. Köln : IQWiG, 2008.

${ }^{3}$ Об утверждении Правил формирования перечней лекарственных препаратов для медицинского применения и минимального ассортимента лекарственных препаратов, необходимых для оказания медицинской помощи : постановление Правительства РФ от 28 авг. 2014 г. № 871 (ред. от 12 июня 2017г.). URL: http://base. garant.ru/70728348; Об утверждении перечня жизненно необходимых и важнейших лекарственных препаратов для медицинского применения на 2017 год : распоряжение Правительства РФ от 28 дек. 2016 г. № 2885. URL: http://government.ru/docs/25924; Об утверждении перечня медицинских изделий, имплантируемых в организм человека при оказании медицинской помощи в рамках программы государственных гарантий бесплатного оказания гражданам медицинской помощи, а также перечня медицинских изделий, отпускаемых по рецептам на медицинские изделия при предоставлении набора социальных услуг : распоряжение Правительства РФ от 22 окт. 2016 г. № 2229-p. URL: http://www.garant.ru/ products/ipo/prime/doc/71422628. отвечает комиссия, в которую входят представители министерств здравоохранения, промышленности и торговли, федеральных образовательных организаций высшего медицинского и фармацевтического образования и др. Необходимость детального изучения роли представителей перечисленных выше учреждений в процессе формирования таких перечней и анализа основных критериев, влияющих на выбор медицинских технологий, обусловила актуальность настоящего исследования.

Наша цель - изучить существующую систему принятия решений о фринансировании лекарственных средств и изделий медицинского назначения. Для реализации указанной цели были поставлены следующие задачи:

1. Анализ научной литературы по изучаемой проблеме.

2. Определение основных организаций, влияющих на принятие решений о финансировании программ льготного лекарственного обеспечения различного уровня (ЖНВЛП, федеральный, региональный уровни и фрормулярные перечни отдельных медицинских организаций).

3. Выделение критериев принятия решений о включении препаратов (медицинских изделий) в перечни льготного финансирования.

4. Оценка необходимого уровня финансирования отдельных социально значимых нозологий и заболеваний, требующих применения высокозатратных технологий.

5. Определение наиболее перспективных направлений развития оценки технологий здравоохранения в России на основании экспертного мнения.

Материалы и методы. В период с сентября по декабрь 2016 г. было проведено анонимное анкетирование экспертов, для чего разработана анкета, содержащая группы вопросов в соответствии с задачами исследования. Анкетирование проводилось на профрильных конференциях, а также на курсах повышения квалификации по специальности «Общественное здоровье и здравоохранение» Национального НИИ общественного здоровья им. Н. А. Семашко.

Для обработки полученных данных были использованы математический, статистический, аналитический методы, а также метод логического обобщения.

Результаты. В исследовании приняли участие 250 чел. По критерию «Профрессиональная деятельность» они были разделены на семь групп. Сведения о группах респондентов приведены в табл. 1. 


\begin{tabular}{|l|r|}
\hline \multicolumn{1}{|c|}{ Профессия / должность } & $\begin{array}{c}\text { Количество } \\
\text { человек (\%) }\end{array}$ \\
\hline Штатный сотрудник Министерства (департамента) здравоохранения & $43(17)$ \\
\hline Врач & $60(24)$ \\
\hline Специалист / эксперт в области оценки технологий здравоохранения & $22(9)$ \\
\hline $\begin{array}{l}\text { Сотрудники образовательных и научных организаций медицинского и фрармацевтического } \\
\text { профилей }\end{array}$ & $71(28)$ \\
\hline ФОМС (страховая компания) & $17(7)$ \\
\hline Общественные организации (в том числе пациентов) & 0 \\
\hline Индустрия (производители и дистрибьюторы) & $37(15)$ \\
\hline
\end{tabular}

Таким образом, четверть опрошенных (60 чел.) работали врачами клинических специальностей, 71 респондент, или $28 \%$, сотрудники образовательных учреждений и научных организаций, 43 (17\%) и 37 (15\%)представители Министерства (департамента) здравоохранения России и индустрии соответственно, 22 чел. (9 \%) - эксперты в области оценки технологий здравоохранения (далее - ОТЗ), 17 чел. (7 \%) - работники страховых компаний. Необходимо отметить, что 20 анкет было направлено представителям общественных организаций, но респонденты данной группы затруднились ответить на поставленные вопросы.

При определении структур, влияющих на принятие решений о включении препаратов в перечень ЖНВЛП, все респонденты отметили, что наибольшую роль в этом играет Министерство здравоохранения России (далее - M3), то же касается и федеральных
Рис. 1. Принятие решений о формировании перечня ЖНВЛП программ льготного лекарственного обеспечения.

Роль региональных министерств здравоохранения отмечена респондентами в отношении региональных программ льготного лекарственного обеспечения, также был выделен средний уровень их значимости при разработке формулярных перечней отдельных медицинских учреждений.

Высокий уровень влияния внештатных клинических специалистов Минздрава России на формирование перечня ЖНВЛП и федеральные программы льготного лекарственного обеспечения отмечен представителями фармацевтических компаний и сотрудниками НИИ и образовательных учреждений, в то время как специалисты министерства и врачи выделили клинических специалистов только в $30 \%$ случаев. Сводная информация по перечням ЖНВЛП и федеральным программам приведена на рис. 1 и 2.

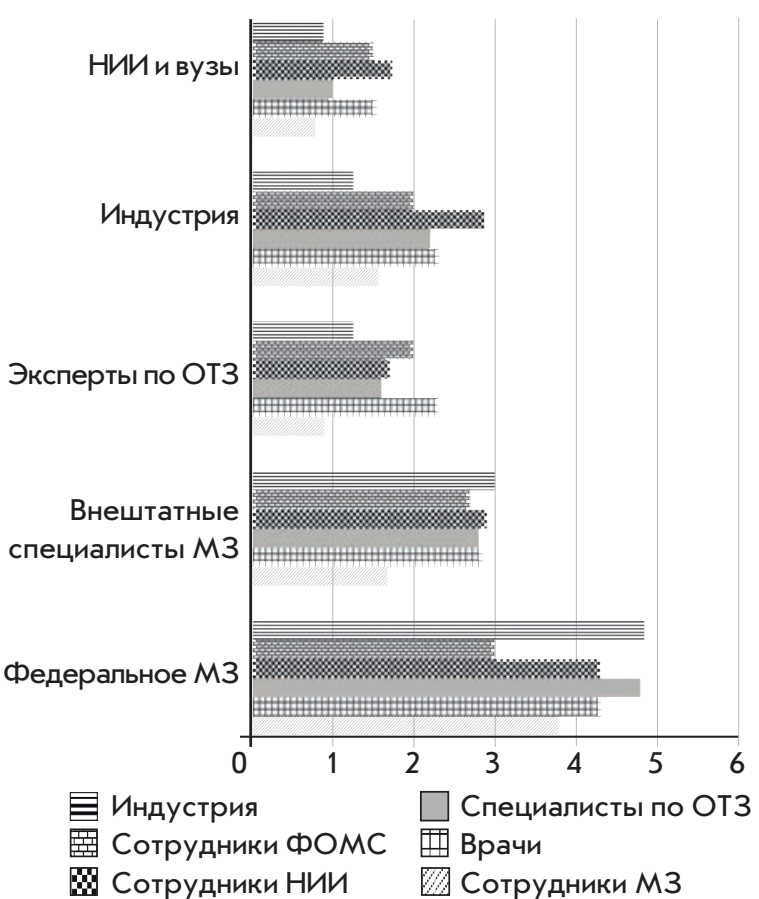

Рис. 2. Принятие решений о формировании федеральных программ льготного лекарственного обеспечения 
В отношении региональных программ льготного лекарственного финансирования и формулярных перечней отдельных медицинских организаций респондентами отмечена лидирующая роль региональных министерств здравоохранения. Также респонденты отмечают влияние индустрии на их формирование. При этом сами представители фрармацевтических компаний не оценивают свою роль столь высоко.

Сотрудники НИИ и медицинских университетов отмечают высокое влияние Минздрава России на формирование формулярных перечней. Сводная информация приведена на рис. 3 и 4.

При анализе ответов респондентов в отношении целесообразного уровня фринансирования терапии социально значимых заболеваний (артериальной гипертензии, сахарного диабета II типа, туберкулеза) диапазон ответов находился в пределах 10-100 тыс. р. в год, в то время как для заболеваний, терапия которых требует применения высокотехнологичных лекарственных препаратов, ответы колебались от 50 тыс. до 10 млн р. в год, что свидетельствует об отсутствии единства мнений.

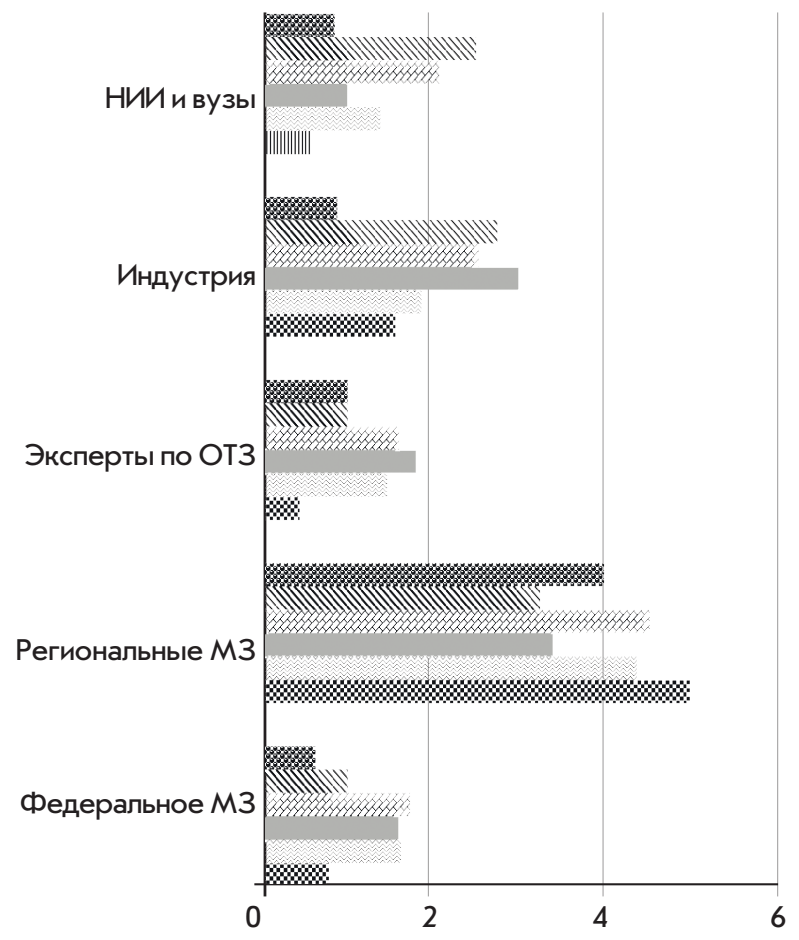
Индустрия
Сотрудники сомС
Специалисты по ОТЗ
○ Сотрудники НИИ
Врачи
Сотрудники M3

Рис. 3. Принятие решений о формировании региональных программ льготного лекарственного обеспечения
Для изучения фракторов, влияющих на принятие решений о включении препаратов в программы льготного лекарственного обеспечения, респондентам предлагалось проранжировать значимость таких параметров, как наличие медицинской технологии в клинических рекомендациях и стандартах ведения пациентов, результаты метаанализов и систематических обзоров, рандомизированных клинических и постмаркетинговых исследований. Полный перечень критериев и результаты оценки по группам приведены в табл. 2.

При оценке критериев, влияющих на принятие решений, установлено, что для представителей Министерства (департамента) здравоохранения России (группа 1) наиболее значимыми являются наличие медицинской технологии в стандартах оказания медицинской помощи и результаты клинико-экономического анализа, факт проведения клинических исследований и полученные в итоге результаты, выражающиеся в конечных, а не суррогатных точках.

Врачи (группа 2) солидарны с коллегами из Министерства (департамента) здравоохранения России в отношении первых двух пунктов, а также выделяют опыт применения в

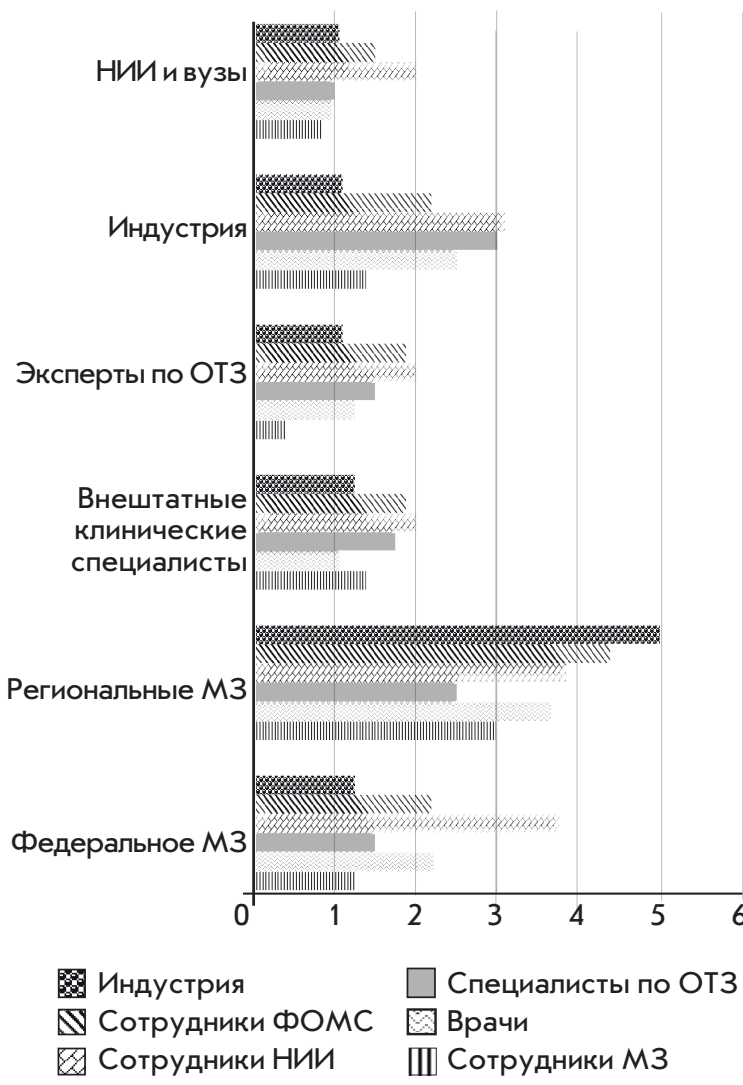

Рис. 4. Принятие решений о формировании формулярных перечней 
Критерии принятия решений о включении препаратов в перечни льготного лекарственного обеспечения

\begin{tabular}{|c|c|c|c|c|c|c|c|c|c|c|c|c|c|c|}
\hline \multirow[b]{2}{*}{$\begin{array}{c}\text { Груп- } \\
\text { пы } \\
\text { ре- } \\
\text { спон- } \\
\text { ден- } \\
\text { тов }\end{array}$} & \multirow[b]{2}{*}{$\begin{array}{c}\text { Инно- } \\
\text { ваци- } \\
\text { онный } \\
\text { меха- } \\
\text { низм } \\
\text { дей- } \\
\text { ствия }\end{array}$} & \multicolumn{3}{|c|}{$\begin{array}{l}\text { Клинические } \\
\text { исследования }\end{array}$} & \multicolumn{2}{|c|}{ Метаанализы } & \multicolumn{3}{|c|}{$\begin{array}{c}\text { Постмаркетинговые } \\
\text { исследования }\end{array}$} & \multirow[b]{2}{*}{$\begin{array}{c}\text { Опыт } \\
\text { при- } \\
\text { мене- } \\
\text { ния на } \\
\text { прак- } \\
\text { тике }\end{array}$} & \multirow[b]{2}{*}{$\begin{array}{c}\text { Мне- } \\
\text { ние } \\
\text { клини- } \\
\text { ческих } \\
\text { специ- } \\
\text { али- } \\
\text { стов }\end{array}$} & \multirow[b]{2}{*}{$\begin{array}{c}\text { Нали- } \\
\text { чие в } \\
\text { реко- } \\
\text { мен- } \\
\text { даци- } \\
\text { ях }\end{array}$} & \multirow[b]{2}{*}{$\begin{array}{c}\text { Нали- } \\
\text { чие в } \\
\text { стан- } \\
\text { дартах } \\
\text { ока- } \\
\text { зания } \\
\text { меди- } \\
\text { цин- } \\
\text { ской } \\
\text { помо- } \\
\text { щи }\end{array}$} & \multirow[b]{2}{*}{$\begin{array}{c}\text { Пока- } \\
\text { затели } \\
\text { клини- } \\
\text { ко- } \\
\text { эконо- } \\
\text { миче- } \\
\text { ской } \\
\text { эф- } \\
\text { фек- } \\
\text { тивно- } \\
\text { сти }\end{array}$} \\
\hline & & \begin{tabular}{|c} 
\\
Факт \\
про- \\
веде- \\
ния
\end{tabular} & $\begin{array}{c}\text { Досто- } \\
\text { верный } \\
\text { поло- } \\
\text { житель- } \\
\text { ный } \\
\text { ре- } \\
\text { зультат } \\
\text { (сурро- } \\
\text { гатные } \\
\text { точки) }\end{array}$ & $\begin{array}{c}\text { Досто- } \\
\text { верный } \\
\text { поло- } \\
\text { житель- } \\
\text { ный } \\
\text { ре- } \\
\text { зультат } \\
\text { (ко- } \\
\text { нечные } \\
\text { точки) }\end{array}$ & $\begin{array}{c}\text { Факт } \\
\text { нали- } \\
\text { чия }\end{array}$ & $\begin{array}{c}\text { Досто- } \\
\text { верный } \\
\text { поло- } \\
\text { жи- } \\
\text { тель- } \\
\text { ный } \\
\text { ре- } \\
\text { зультат }\end{array}$ & $\begin{array}{c}\text { Факт } \\
\text { про- } \\
\text { веде- } \\
\text { ния }\end{array}$ & $\begin{array}{c}\text { Досто- } \\
\text { верный } \\
\text { поло- } \\
\text { житель- } \\
\text { ный } \\
\text { ре- } \\
\text { зультат } \\
\text { (сурро- } \\
\text { гатные } \\
\text { точки) }\end{array}$ & \begin{tabular}{|c} 
Досто- \\
верный \\
поло- \\
житель- \\
ный \\
ре- \\
зультат \\
(ко- \\
нечные \\
точки)
\end{tabular} & & & & & \\
\hline 1 & 2,56 & 3,78 & 3,22 & 3,89 & 2,22 & 2,78 & 1,67 & & 3,22 & 3,33 & 3,22 & 3,56 & 4,00 & 4,00 \\
\hline 2 & 2,42 & 3,08 & 3,17 & 3,25 & 2,17 & 2,58 & 1,50 & 2,42 & 2,00 & 3,83 & 3,83 & 3,75 & 4,08 & 4,42 \\
\hline 3 & 2,20 & 1,80 & 3,40 & 3,60 & 1,60 & 2,20 & 1,80 & 1,80 & 1,80 & 2,20 & 3,20 & 3,20 & 2,80 & 2,80 \\
\hline 4 & 1,93 & 3,53 & 3,33 & 3,73 & 2,67 & 2,47 & 2,00 & 2,20 & 2,27 & 4,20 & 3,33 & 3,80 & 3,73 & 2,93 \\
\hline 5 & 1,00 & 2,50 & 1,75 & 2,25 & 1,50 & 0,50 & 3,00 & 2,00 & 1,50 & 3,25 & 2,75 & 3,00 & 3,75 & 2,50 \\
\hline 6 & 1,88 & 3,63 & 3,25 & 2,75 & 1,75 & 2,63 & 1,13 & 1,63 & 1,63 & 3,13 & 4,00 & 2,75 & 3,50 & 2,50 \\
\hline
\end{tabular}

клинической практике и мнение других специалистов как наиболее значимые критерии.

Специалисты по ОТЗ (группа 3) оценили положительный результат клинических исследований (конечные точки) как наиболее значимый, далее они выбрали такие критерии, как мнение клинических специалистов и наличие в клинических рекомендациях.

От представителей медицинских университетов и НИИ (группа 4) были получены аналогичные ответы, однако мнение клинических специалистов они оценили несколько ниже, выделив фракт проведения клинических исследований как значимый критерий.

Респонденты из страховых организаций (группа 5) оценивают наличие медицинских технологий в стандартах (клинических рекомендациях), а также опыт их применения на практике как наиболее значимые критерии.

Представители индустрии (группа 6) выделяют факт проведения клинических исследований, их положительные результаты (суррогатные конечные точки) и наличие медицинских технологий в стандартах оказания медицинской помощи.

В заключительной части анкеты респонденты ответили на вопросы, посвященные перспективам развития ОТЗ в России. В качестве основной проблемы, затрудняющей внедрение данных технологий, было выде- лено отсутствие законодательной базы. Респонденты считают наиболее оптимальными для нашей страны модели Великобритании и Канады. Система может быть внедрена в нашей стране через шесть - десять лет. В качестве источника финансирования респонденты отмечают средства государства.

Выводы. Система принятия решений в России зависит от уровня программы: можно выделить ЖНВЛП, федеральный, региональный уровни и уровень отдельной организации. Это необходимо учитывать при разработке стратегии внедрения ОТЗ как инструмента принятия решений.

Министерство здравоохранения России, внештатные клинические специалисты министерства и фрармацевтические компании имеют наибольший вес при принятии решений о формировании перечней лекарственного финансирования.

Роль медицинских технологий по-прежнему невелика, определяющими фракторами являются их наличие в стандартах лечения, клинических рекомендациях и мнение клинических специалистов.

Это требует изменения нормативной базы системы принятия решений о включении препаратов в программы льготного лекарственного обеспечения на федеральном уровне.

\section{СПИСОК ИСПОЛЬЗОВАННОЙ ЛИТЕРАТУРЫ}

1. Хабриев Р. У. Оценка технологий здравоохранения / Р. У. Хабриев, Р. И. Ягудина, Н. Г. Правдюк. - М. : Мед. информ. агентство, 2013. - 405 с.

2. Stevens A. 'Quick and Clean': authoritative health technology assessment for local health care contracting / A. Stevens, D. Colin-Jones, J. Gabbay / / Health Trends. - 1995. — Vol. 27, № 2. - P. 37-42. 
3. Kolominsky-Rabas P. L. The Hanover Consensus: helpful for German Decision-Makers? / P. L. Kolominsky-Rabas, J. J. Caro / / Value in Health. - 2008. - Vol. 11, № 4. - P. 545-546.

4. Fricke F.-U. Health Technology assessment: a Perspective from Germany / F.-U. Fricke, H. P. Dauben // Value in Health. - 2009. - Vol. 12, suppl. 2. - P. S20-S27.

\section{REFERENCES}

1. Khabriev R. U., Yagudina R. I., Pravdyuk N. G. Otsenka tekhnologii zdravookhraneniya [Health Technology Assessment]. Moscow, Medicinal information agency Publ., 2013. 405 p.

2. Stevens A., Colin-Jones D., Gabbay J. 'Quick and Clean': Authoritative Health Technology Assessment for Local Health Care Contracting. Health Trends, 1995, vol. 27, no. 2, pp. 37-42.

3. Kolominsky-Rabas P. L., Caro J. J. The Hanover Consensus: Helpful for German Decision-Makers? Value in Health, 2008, vol. 11, no. 4, pp. 545-546.

4. Fricke F.-U., Dauben H. P. Health Technology Assessment: a Perspective from Germany. Value in Health, 2009, vol. 12, suppl. 2, pp. S20-S27.

\section{Информация об авторах}

Хабриев Рамил Усманович - академик РАН, доктор медицинских наук, доктор фармацевтических наук, профессор, директор, Национальный НИИ общественного здоровья им. Н. А. Семашко, 105064, г. Москва, ул. Воронцово Поле, 12, стр. 1, e-mail: institute@nriph.ru, http://orcid.org/00000003-2283-376X.

Суходолов Александр Петрович - доктор экономических наук, профессор, заслуженный экономист Российской Федерации, ректор, Байкальский государственный университет, 664003, г. Иркутск, ул. Ленина, 11, e-mail: rector@bgu.ru.

Спасенников Борис Аристархович - доктор медицинских наук, доктор юридических наук, профессор, главный научный сотрудник, НИИ Федеральной службы исполнения наказаний России, 125130, г. Москва, ул. Нарвская, 15a, e-mail: borisspasennikov@ yandex.ru, http: / / orcid.org/0000-0002-5668-6457.

Безмельницына Людмила Юрьевна - кандидат медицинских наук, ведущий научный сотрудник, Национальный НИИ общественного здоровья им. Н. А. Семашко, 105064, г. Москва, ул. Воронцово Поле, 12, стр. 1, e-mail: blyu18@gmail.com.

Мешков Дмитрий Олегович - доктор медицинских наук, руководитель отдела, Национальный НИИ общественного здоровья им. Н. А. Семашко, 105064 , г. Москва, ул. Воронцово Поле, 12, стр. 1, e-mail: meshkovdo@nriph.ru.

\section{Для цитирования}

Хабриев Р. У. Система принятия решений в программе льготного лекарственного обеспечения / Р. У. Хабриев, А. П. Суходолов, Б. А. Спасенников, Л. Ю. Безмельницына, Д. О. Мешков // Известия Байкальского государственного университета. - 2018. - T. 28, № 1. - C. 6-11. - DOI: $10.17150 / 2500-2759.2018 .28(1) .6-11$.

\section{Authors}

Ramil U. Khabriev - Academician of the Russian Academy of Sciences, DSc in Medicine, DSc in Pharmacy, Professor, Director of the N. A. Semashko National Research Institute for Public Health, 12-1 Vorontsovo Pole St., 105064, Moscow, the Russian Federation, e-mail: institute@nriph.ru, http://orcid.org/00000003-2283-376X.

Alexander P. Sukhodolov - DSc in Economics, Professor, meritorious economist of the Russian Federation, Rector of Baikal State University, 11 Lenin St., 664003, Irkutsk, the Russian Federation, e-mail: rector@bgu.ru.

Boris A. Spasennikov - DSc in Medicine, DSc in Law, Professor, Chief Researcher of the Research Institute of the Federal Penitentiary Service, 15-A Narvskaja St., 125130, Moscow, the Russian Federation, e-mail: borisspasennikov@yandex.ru, http://orcid. org/0000-0002-5668-6457.

Lyudmila Y. Bezmelnitsyna - PhD in Medicine, Leading Researcher, N. A. Semashko National Research Institute for Public Health, 12-1 Vorontsovo Pole St., 105064, Moscow, the Russian Federation, e-mail: blyu18@gmail.com.

Dmitry O. Meshkov - DSc in Medicine, Head of department, N. A. Semashko National Research Institute for Public Health, 12-1 Vorontsovo Pole St., 105064, Moscow, the Russian Federation, e-mail: meshkovdo@ nriph.ru.

\section{For citation}

Khabriev R. U., Sukhodolov A. P., Spasennikov B. A., Bezmelnitsyna L. Y., Meshkov D. O. The DecisionMaking System in the Program of Subsidized Pharmaceutical Provision. Izvestiya Baykal'skogo gosudarstvennogo universiteta = Bulletin of Baikal State University, 2018, vol. 28, no. 1, pp. 6-11. DOl: 10.17150/2500-2759.2018.28(1).6-11. (In Russian). 